\section{Victoria Michell}

Practice Management Consultant

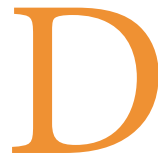
isputes can arise for any number of reasons within a dental practice; from financial issues to personal or professional disputes between practice personnel. The majority of disputes we see escalate are caused by communication issues. Even the best of communicators or those like myself who have taken courses on the subject can communicate poorly and the fallout from a poor communication can be financially and emotionally costly. Now that the pandemic is upon us the methods of communication have been restricted to, in the most-part, remote communications or with part of the face covered. Where we would have always advised BDA members to speak to staff, associates and patients face-to-face to resolve issues so that communication is clearer and miscommunication easier to spot by both parties, we now advise members to do this over the telephone, by video call or at a sufficient distance. These barriers make communication more difficult, even for the most seasoned communicator, and is one reason the need for mediation may increase now more than ever.

Currently many disputes arising between members are a result of the lack of clear guidance as to how situations pertaining to COVID-19 should be dealt with now and in the future. The very nature of the pandemic means that we do not know what is coming next and along with contractual and financial uncertainty facing practice owners, associates and staff alike, the emotional strain this uncertainty causes is having a big impact on everyone. This situation creates a hotbed for disputes and when combined with social distancing makes conflict resolution challenging and increases the need for the assistance of a mediator.

Mediation is a dispute resolution method that helps parties reach agreements by opening up channels of communication between parties. Mediators do not decide on the merits of arguments or impose solutions on the parties but instead they encourage parties to express their problems and potential solutions in a way that diffuses conflicts and allows parties to sort their own conflicts. It is an attractive option for many who are seeking to preserve relationships, solve problems quickly and avoid costly litigation. Many disputes are best discussed with parties sitting in a room face-to-face but at the time of writing this is not possible.

\section{The BDA's mediation model}

The government's instructions are clear that those who can work from home should and so the BDA has turned to remote mediations. Therefore, we are running mediations using video conferencing. Certain challenges arise from reading body language to building rapport with the parties via this median. Nothing can replace a face-to-face meeting but there are certain benefits to video conferencing. It allows an agenda to be stuck to more tightly than is often the case when the parties are in the room and can take some of the emotion out of a discussion which can work towards diffusing tension.

We held its first remote mediation in early July and the following became apparent. Remote mediation is not very different to face-to-face meditation. The new environment did not seem to hinder the parties' ability to discuss matter with each other constructively and work collaboratively to resolve the situation. Perhaps the ability to discuss matters in familiar and comfortable surroundings and walk away from the screen to take a break made up for the physical barrier of the screen.

\section{Steps you can take to mitigate the risk of a dispute}

Listen to those speaking to you. On the phone, via a video call or even a quick chat in the surgery corridor can lead to someone who is usually perceptive and would pick up non-verbal cues, missing the early signs of problems brewing. Listen carefully to what someone is saying. Are they making a complaint but too nervous to voice it or is there more to a throw away comment than initially thought? Give those talking a bit more time to speak and make sure they understand they are being heard.

Acknowledge the pandemic. In communication terms this means telling staff, associates and patients that there are barriers in the way of communication but emphasise that you want to hear any issues they have and particularly if they feel that you could be communicating better. Ask them to raise issues they have with you as soon as possible as the new environment will make them more difficult for you to spot.

Understand that the pandemic is putting everyone under increased stress and strain. No one can really understand the long term effects this will have on us all but in the short term people are dealing with different responsibilities both in work and outside and this will effect no two same people in the same way. By just being aware of this you will be able to listen better and make allowances for people not communicating with you as well as they may do otherwise. This in turn will give you the perspective to avoid conflicts you may otherwise be drawn into.

https://doi.org/10.1038/s41404-020-0469-6 